\title{
Ultrafast Laser Engraving Method to Fabricate Gravure Plate for Printed Metal-Mesh Touch Panel ${ }^{\dagger}$
}

\author{
Weiyuan Chen ${ }^{1}$, Wenlang Lai ${ }^{1}$, Yuming Wang ${ }^{1}$, Kaijun Wang ${ }^{1}$, Shengyu Lin ${ }^{1}$, Yuli Yen ${ }^{1,2}$, \\ Hong Hocheng ${ }^{2}$ and Tahsin Chou ${ }^{1, *}$
}

Received: 9 July 2015 ; Accepted: 26 September 2015 ; Published: 5 October 2015

Academic Editor: Maria Farsari

1 Mechanical and System Research Laboratories, Industrial Technology Research Institute, No. 195, Sec. 4, Chung Hsing Road, Chutung, Hsinchu 31040, Taiwan; weiyuanchen@itri.org.tw (W.C.); alanlai@itri.org.tw (W.L.); ymwang@itri.org.tw (Y.W.); kg_wang@itri.org.tw (K.W.); rita_lin@itri.org.tw (S.L.); itri450908@itri.org.tw (Y.Y.)

2 Department of Power Mechanical Engineering, National Tsing Hua University, No. 101, Sec. 2, Kuang Fu Road, Hsinchu 30013, Taiwan; hocheng@pme.nthu.edu.tw

* Correspondence: tahsinchou@itri.org.tw; Tel.: +886-3591-6791; Fax: +886-3582-0043

$\dagger \quad$ This paper is an extended version of our paper published in the 6th International Conference of Asian Society for Precision Engineering and Nanotechnology (ASPEN2015), Harbin, China, 15-19 April 2015.

\begin{abstract}
In order to engrave gravure plate with fine lines structures, conventional art used lithography with dry/wet etching. Lithography with dry/wet etching method allows to engrave lines with smooth concave shape, but its disadvantages include difficulty in controlling aspect ratio, high and uniform in large size process, substrate material limitation due to etching solution availability, and process complexity. We developed ultra-fast laser technology to directly engrave a stainless plate, a gravure plate, to be used for fabricating $23 \mathrm{in}$. metal-mesh touch panel by gravure offset printing process. The technology employs high energy pulse to ablate materials from a substrate. Because the ultra-fast laser pulse duration is shorter than the energy dissipation time between material lattices, there is no heating issue during the ablation process. Therefore, no volcano-type protrusion on the engraved line edges occurs, leading to good printing quality. After laser engraving, we then reduce surface roughness of the gravure plate using electro-polishing process. Diamond like carbon (DLC) coating layer is then added onto the surface to increase scratch resistance. We show that this procedure can fabricate gravure plate for gravure offset printing process with minimum printing linewidth $10.7 \mu \mathrm{m}$. A 23 in. metal-mesh pattern was printed using such gravure plate and fully functional touch panel was demonstrated in this work.
\end{abstract}

Keywords: ultrafast laser; gravure offset printing; gravure plate; metal-mesh touch panel

\section{Introduction}

Printing process provides a fast, continuous production with low production costs and pollution, and becomes a key process technology in printed electronics [1,2]. These processes need only one-step process to transfer pattern onto target surface, studied by Pudas et al., Lee et al., and Chun et al. [3-5]. Owing to its high line resolution, the gravure offset printing technology may replace the current photolithography process and is considered as the advanced manufacturing technology for next generation electronic products [6].

The key issue of gravure offset printing process is the gravure plate, which transfers the designed pattern to be printed. There are three different engraving methods that can be used for fabricating gravure plate. These methods include wet etching, electroforming [7], and ultra-fast laser direct ablation. Fabricating gravure plate by electroforming is a replication process and not the original 
structuring process. Fabricating gravure plate by wet etching process after lithography is popular in industry. However, the major disadvantage of wet etching process is isotropic etching phenomenon. It is difficult to make the high aspect ratio of the groove substrate. Furthermore, the etchant chemicals have to be continuously replaced in order to keep the same initial etching rate, and the choice of substrate material is limited by the availability of the etchant chemicals. The method to fabricate gravure plates described in this research is ultra-fast laser direct ablation. A laser beam is focused onto the surface of the gravure plate to fabricate the pattern. Comparing with ablation using nanosecond pulses laser, the ultra-fast laser ablation has little or no collateral damage from shock waves and heat conduction produced during the material being processed [8]. Using dimensional analysis, the conduction time in SUS304 steel plate is at the range of millisecond and nanosecond. Comparing to the two methods mentioned before, ultra-fast laser direct ablation has advantages of short production time and well uniformity [8-10].

The great demand for alternative solutions for indium tin oxide (ITO) has arisen due to several intrinsic drawbacks ITO's. The transparent conducting electrodes can be made by metal material through by laser ablation [11], lithography, and printing process. The printing process has the advantage in cost and throughput.

In this study, an ultra-fast laser engraving system is established to fabricate $23 \mathrm{in}$. metal-mesh gravure plate. In order to enhance the ink transfer rate, electrolytic polished process [12] is used to decrease the roughness of groove engraved by laser. Then, the gravure plate is deposited with diamond like carbon (DLC) to protect the surface against scratches and abrasion by the doctor blade during printing process. Finally, the gravure plate can be manufactured by optimal machining parameters and successfully used for printing the 23 in. metal-mesh touch sensor circuits with linewidth of approximately $10 \mu \mathrm{m}$.

\section{Femtosecond Laser System and Machining Process}

Figure 1 shows the schematic diagram of the ultra-fast laser engraving system used to engrave 23 in. metal-mesh circuit patterns on the steel substrate. The laser source is a commercial ytterbium laser (HIGH Q LASER, FemtoREGEN, Rankweil, Austria), that generates 350 fs laser pulses with a maximum pulse energy of $20 \mu \mathrm{J}$ at a $100 \mathrm{kHz}$ repetition rate and central wavelength of $\lambda=1035 \mathrm{~nm}$. A galvo scanner system is embodied in the laser machining system, which makes the process speed up to $3000 \mathrm{~mm} / \mathrm{s}$. The diameter of laser beam spot size is $13 \mu \mathrm{m}$, and the beam quality is $\mathrm{M} 2<1.2$. The workpiece is placed on the vacuum chuck and machined by galvo scanner system at various feed rates. After machining process, the workpiece is rinsed for $10 \mathrm{~min}$ with alcohol in an ultrasonic cleaner to remove any debris from the ablation process and finally electrolytic polished process.

In this study, a gravure plate which has $15 \mu \mathrm{m}$ of inner metal-mesh circuits and $70 \mu \mathrm{m}$ outer circuits. Due to the difference of line width between inner metal-mesh and outer circuit, this study utilizes the spiral feeding machining method to engrave the groove with various widths is proposed.

(a)

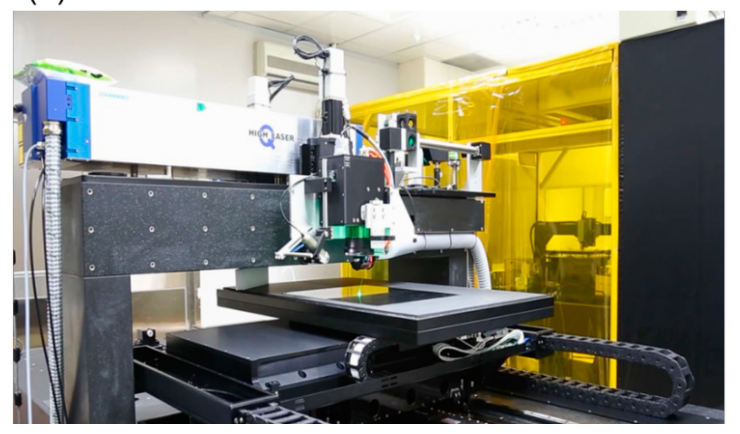

(b)

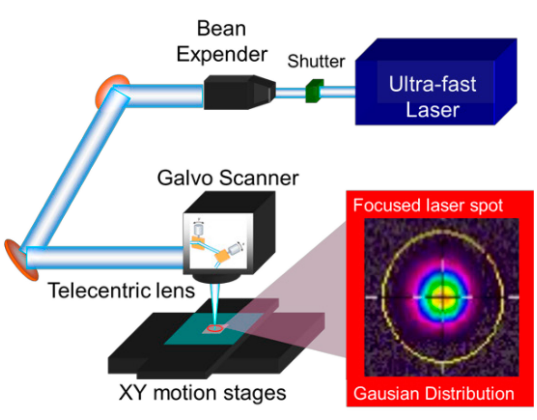

Figure 1. (a) The ultra-fast laser engraving system; and (b) Gaussian beam profile of the ultra-fast laser. 


\section{Fabrication of 23 In. Metal-Mesh Circuits Gravure Plate}

The dimensions of groove on gravure plate machined by ultra-fast laser engraving system are related to the parameters of laser fluence, spiral width, and cover rate of spiral path.

Figure 2 shows the relationship between the groove width and laser fluence varied from 1.2 to $2.7 \mathrm{~J} / \mathrm{cm}^{2}$. The groove width is increased linearly with the laser fluence. Figure 2 also shows the relationship between the groove width and the cover rate at the spiral width of $5 \mu \mathrm{m}$, and machining speed with $20 \mathrm{~mm} / \mathrm{s}$. Three levels of cover rate, included $50 \%, 65 \%$, and $80 \%$, are used for experiments. When the cover rate reaches $80 \%$, the width of groove is clearly wider than lower cover rates. The results in more energy accumulated at high cover rate. Due to the two different groove widths between outer circuit and inner mesh structure, we can adjust spiral width to achieve the purpose. There are two types of spiral widths $(\Omega 1=5 \mu \mathrm{m} ; \Omega 2=10 \mu \mathrm{m})$ used in experiments, as shown in Figure 3, and the experimental result shows that the wider spiral width leads to wider groove width.

The experimental results show that the cover rate and spiral width do not have an obviously affect for the groove depth. Figure 4 shows the relationship between the depth of groove and the laser fluence under the condition of spiral width of $5 \mu \mathrm{m}$, engraving speed of $20 \mathrm{~mm} / \mathrm{s}$, and cover rate of $50 \%$. When the laser fluence and cover rate are increased, the depths of groove are increased linearly.

Figure 5 shows the linewidth of groove is measured by optical microscope and sampled by nine points on gravure plate. The average linewidth of groove is $14.7 \mu \mathrm{m}$, and the standard deviation is $0.266 \mu \mathrm{m}$. The result of standard deviation shows that the gravure plate made by ultra-fast laser engraving system is uniform.

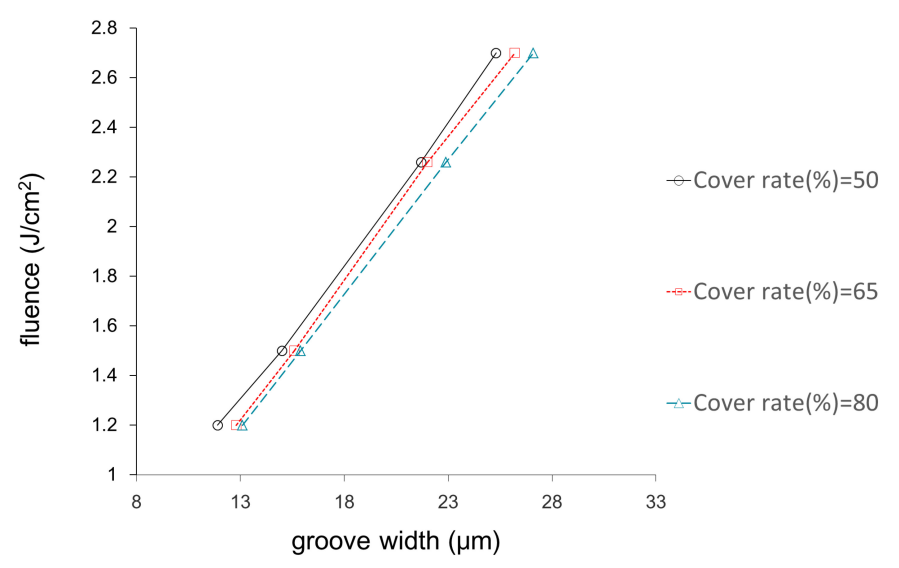

Figure 2. The relationship between the groove width and laser fluence at different cover rate.

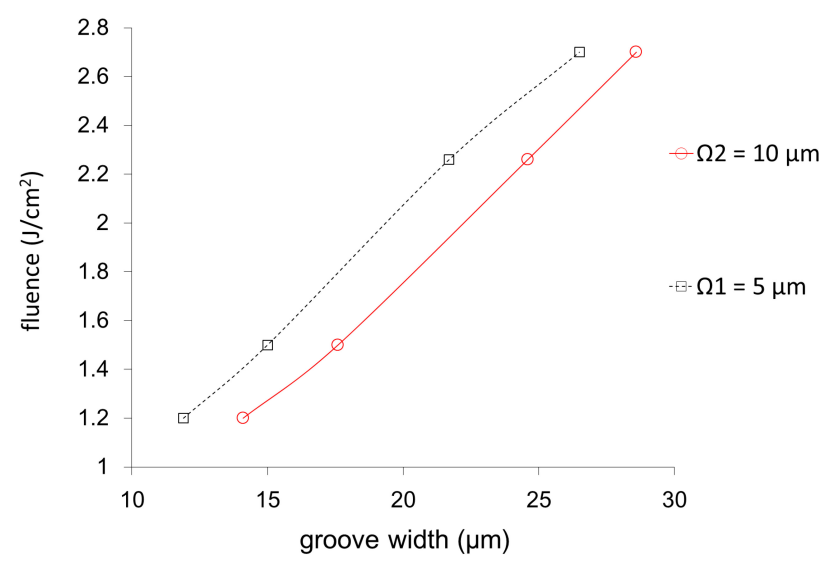

Figure 3. The relationship between the groove width and laser fluence at different spiral width. 


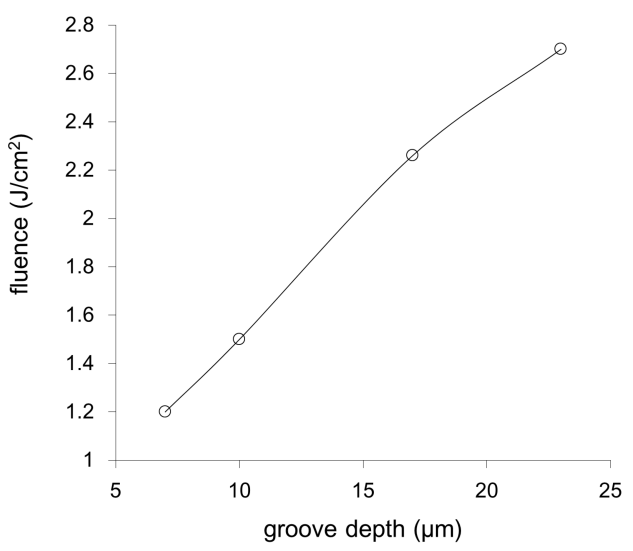

Figure 4. The relationship between the groove depth and laser fluence.

\begin{tabular}{|c|c|}
\hline Position & Line width $(\boldsymbol{\mu m})$ \\
\hline 1 & 14.8 \\
\hline 2 & 14.65 \\
\hline 3 & 14.95 \\
\hline 4 & 15.05 \\
\hline 5 & 14.45 \\
\hline 6 & 14.2 \\
\hline 7 & 14.85 \\
\hline 8 & 14.8 \\
\hline 9 & 14.55 \\
\hline
\end{tabular}

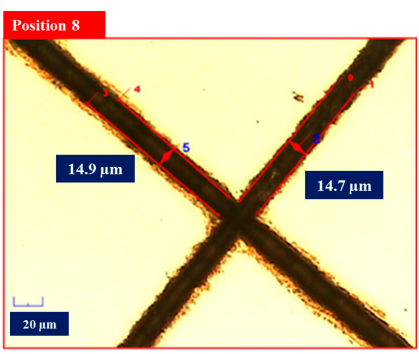

Figure 5. 9 points measurement and picture of gravure plate.

After engraving process by ultra-fast laser engraving system, the gravure plate is rinsed for $10 \mathrm{~min}$ with alcohol in an ultrasonic cleaner to remove any debris from the ablation process. Owing to enhance the ink transfer rate, the gravure plate needs another surface treatment, electrolytic polish. After the polished process, the roughness of the inner groove is reduced and suitable for printing process, as shown in Figure 6. The gravure plate is ready for gravure offset printing process.

In order to protect the gravure plate from scratching in the doctor blade during the printing process, the diamond like carbon (DLC) material is deposited on the surface of gravure plate. The DLC material is the high hardness material and used for many applications [13]. Figure 7 shows the 23 in. metal-mesh circuits gravure plate with $2 \mu \mathrm{m}$ thickness DLC coating layer.
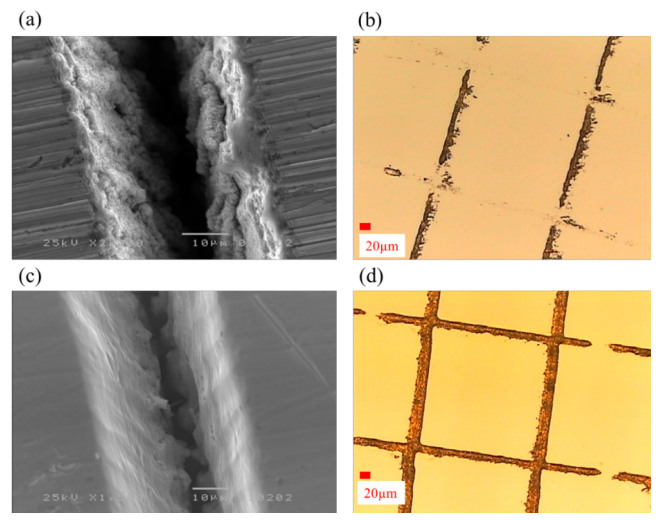

Figure 6. The gravure plate without and with surface treatment of (a) before electrolytic polishing; (b) bad ink transfer rate of non-treatment gravure plate; (c) after electrolytic polishing; and (d) good ink transfer rate of electro-polished gravure plate. 


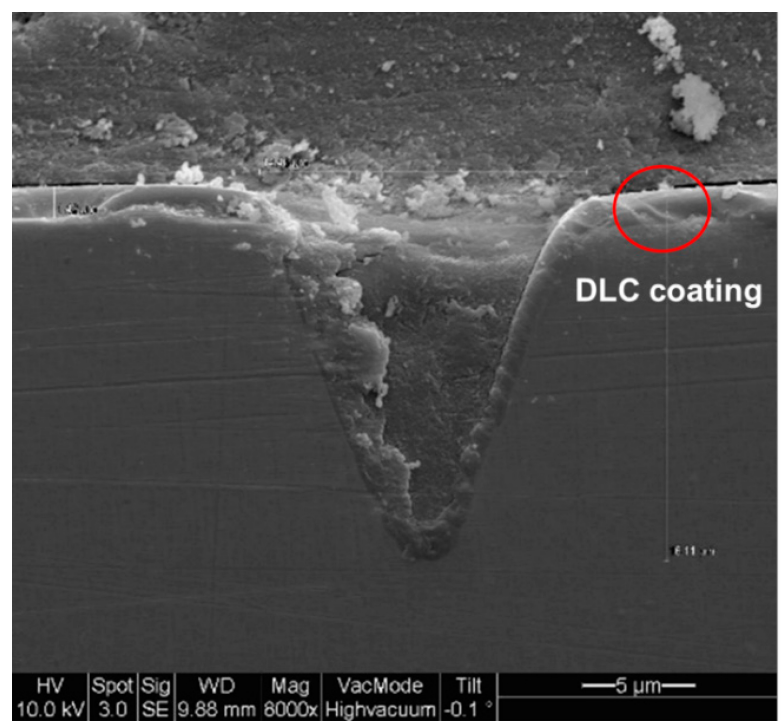

Figure 7. The Scanning electron microscope (SEM) cross-section picture of diamond like carbon (DLC) coating layer.

\section{Gravure Offset Printing Process of 23 In. Metal-Mesh Touch Sensor}

In this study, gravure offset printing process is used to fabricate the $23 \mathrm{in}$. metal-mesh touch panel, as shown in Figure 8. First, the ink is scratched into the grooves of a gravure plate by the doctor blade. During the optimum parameters, the grooves are filled completely and all of the ink is removed from non-patterned areas. Second, the ink is picked up from the gravure plate grooves with an offset material called blanket. The blanket is fixed on a roller called blanket roller. When the ink is picked up on the blanket, the roller rotates forward and presses the ink onto the substrate. In this study, the silver nanoparticle ink developed in our laboratory is used for the gravure offset printing.

The printed silver fine lines are used for metal-mesh touch sensor, as shown in Figures 9 and 10. The optimal laser machining parameters used to fabricate the pattern on SUS304 gravure plate are at specific laser power of $180 \mathrm{~mW}$, spiral width of $40 \mu \mathrm{m}$, and cover rate of $50 \%$ for outer circuit. The parameters at spiral width of $5 \mu \mathrm{m}$ and cover rate $50 \%$ are used for inner circuit. The average line width for printed inner circuits measured by optical microscope and sampled by nine points on the gravure plate is $10.7 \mu \mathrm{m}$, and the standard deviation is approximately $0.7 \mu \mathrm{m}$, as shown in Figure 9 . The average line width of outer circuit is nearly $70 \mu \mathrm{m}$. The $23 \mathrm{in}$. metal-mesh touch sensor is finally fabricated by gravure offset printing process and assembled for touch panel in this study. The $23 \mathrm{in}$. metal-mesh touch panel is demonstrated the touch function successfully, as shown in Figure 10.

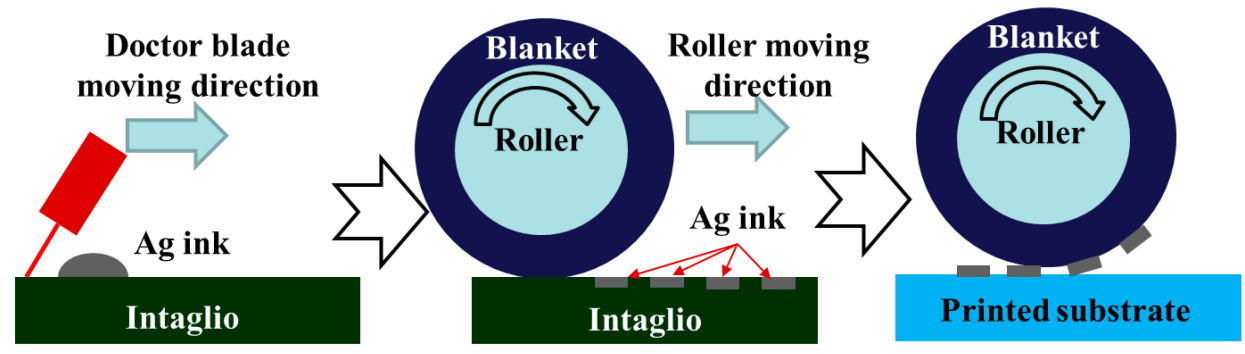

Figure 8. Schematic diagram of gravure offset printing process. 
(a)

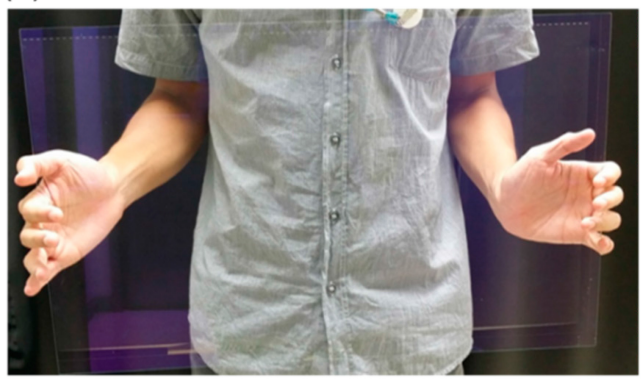

(b)

(c)
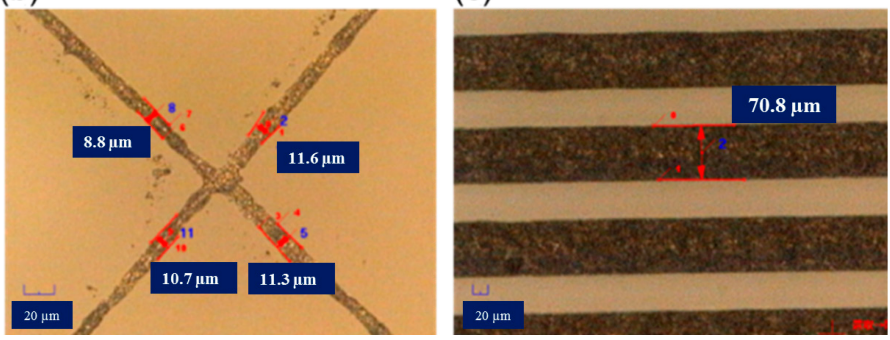

Figure 9. (a) The picture of 23 in. metal-mesh printed sample; (b) Picture of inner metal mesh of printing sample; and (c) Picture of outer circuit of printing sample.

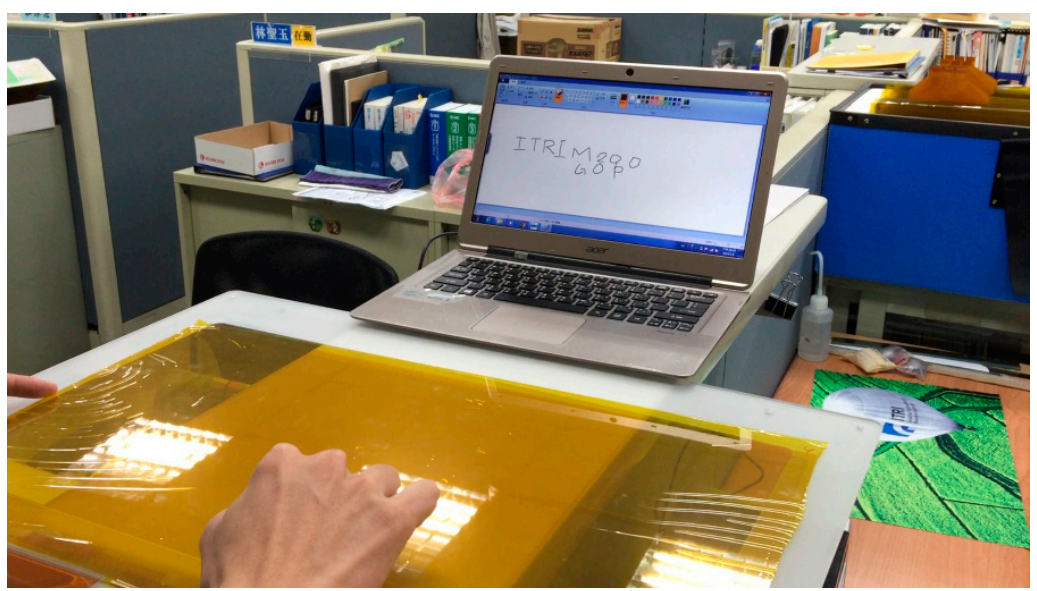

Figure 10. Demonstration of 23 in. metal-mesh touch sensor.

\section{Conclusions}

In this study, the $23 \mathrm{in.} \mathrm{gravure} \mathrm{plate} \mathrm{has} \mathrm{been} \mathrm{completed} \mathrm{by} \mathrm{using} \mathrm{ultra-fast} \mathrm{laser} \mathrm{engraving}$ system, and used to print the metal-mesh circuits on glass. The touch panel with printed metal-mesh circuits on glass has been successfully demonstrated touch function after bonding integrated circuit chips. Using spiral feed of laser beam produces higher aspect ratio of the groove on gravure plate, which is considered advantageous for the printed lines to be narrow and thick to meet the requirements of fine pattern as well as electrical conduction. In the current study, the width of groove in gravure plate is $14.7 \mu \mathrm{m}$, and the width of printed line is $10.7 \mu \mathrm{m}$, which is within the required specifications of the metal-mesh circuits on touch sensor in the display industry.

Acknowledgments: This work was supported by the Ministry of Economic Affairs (MOEA) of Taiwan (under the grant number of E353C11100). 
Author Contributions: Tahsin Chou, Yuming Wang, Weiyuan Chen and Wenlang Lai proposed the idea; Weiyuan Chen and Wenlang Lai performed ultrafast laser engraving experiment and analysis; Yuming Wang, Kaijun Wang, Shengyu Lin, and Yuli Yen performed gravure offset printing process and touch sensor verification. Weiyuan Chen and Tahsin Chou prepared the manuscript; Hong Hocheng contributed to give valuable suggestions on the experimental methods.

Conflicts of Interest: The authors declare no conflict of interest.

\section{References}

1. Gamota, D. Printed Organic and Molecular Electronics; Kluwer Academic Publishers: Boston, MA, USA, 2004.

2. Pudas, M.; Hagberg, J.; Leppävuori, S. Printing parameters and ink components affecting ultra-fine-line gravure-offset printing for electronics applications. J. Eur. Ceram. Soc. 2004, 24, 2943-2950. [CrossRef]

3. Lee, T.M.; Choi, Y.J.; Nam, S.Y.; You, C.W.; Na, D.Y.; Choi, H.C.; Shin, D.Y.; Kim, K.Y.; Jung, K.I. Color filter patterned by screen printing. Thin Solid Film 2008, 516, 7875-7880. [CrossRef]

4. Pudas, M.; Hagberg, J.; Leppävuori, S. The absorption ink transfer mechanism of gravure offset printing for electronic circuitry. IEEE Trans. Electron. Packag. Manuf. 2002, 25, 335-343. [CrossRef]

5. Chun, S.; Grudinin, D.; Lee, D.; Kim, S.H.; Yi, G.R.; Hwang, I. Roll-to-roll printing of silver oxide pastes and low temperature conversion to silver patterns. Chem. Mater. 2009, 21, 343-350. [CrossRef]

6. Choi, S.J.; Lee, S.; Han, K.K. Photodefinable organofunctionalized inorganic dielectric for organic thin film transistors. Appl. Phys. Lett. 2007, 90, 063507. [CrossRef]

7. Hagberg, J.; Leppävuori, S. Method for the manufacturing of high quality gravure plates for printing fine-line electrical circuits. Proc. SPIE 1999, 3892, 313-320.

8. Nolte, S.; Momma, C.; Jacobs, H.; Tunnermann, A.; Chichkov, B.N.; Wellegehausen, B.; Welling, H. Ablation of metals by ultrashort laser pulses. J. Opt. Soc. Am. B 1997, 14, 2716-2722. [CrossRef]

9. Gamaly, E.G.; Rode1, A.V.; Tikhonchuk, V.T.; Luther-Davies, B. Ablation of solids by femtosecond lasers: Ablation mechanism and ablation thresholds for metals and dielectrics. Phys. Plasmas 2002, 9, 949-957. [CrossRef]

10. Föhl, C.; Breitling, D.; Dausinger, F. Precise drilling of steel with ultrashort pulsed solid state lasers. Proc. SPIE 2003, 5121, 271-279.

11. Paeng, D.; Yoo, J.H.; Yeo, J.; Lee, D.; Kim, E.; Ko, S.H.; Grigoropoulos, C.P. Low-Cost Facile Fabrication of Flexible Transparent Copper Electrode by Nanosecond Laser Ablation. Adv. Mater. 2015, 27, $2762-2767$. [CrossRef] [PubMed]

12. Lee, S.J.; Lai, J.J. The effects of electropolishing (EP) process parameters on corrosion resistance of $316 \mathrm{~L}$ stainless steel. J. Mater. Process. Technol. 2003, 140, 206-210. [CrossRef]

13. Zhang, W.; Tanaka, A.; Xu, B.S.; Yoga, K. Study on the diamond-like carbon multilayer films for tribological application. J. Diam. Relat. Mater. 2005, 14, 1361-1367. [CrossRef]

(C) 2015 by the authors; licensee MDPI, Basel, Switzerland. This article is an open access article distributed under the terms and conditions of the Creative Commons by Attribution (CC-BY) license (http://creativecommons.org/licenses/by/4.0/). 